\title{
STAPHYLOCOCCUS AUREUS EM ALIMENTOS
}

\author{
Staphylococcus aureus in food
}

Staphylococcus aureus em alimentos

\section{Amanda Campos Feitosa*1, Rosimeire Mendes Rodrigues ${ }^{2}$, Edwin Angel Torres Torres ${ }^{1}$, Juliana Fonseca M. Silva ${ }^{3}$}

${ }^{1}$ Laboratório de Processos e Separação de Biomoléculas e Desidratação (LAPSDEA), Curso Engenharia de Alimentos, Universidade Federal do Tocantins - UFT, Palmas, Tocantins, Brasil.

${ }^{2}$ Laboratório de Ciências Básicas e da Saúde (LACIBS), Curso Nutrição, Universidade Federal do Tocantins UFT, Palmas, Tocantins, Brasil.

${ }^{3}$ Laboratório de Microbiologia Geral e Aplicada (LMGA), Curso Medicina, Universidade Federal do Tocantins UFT, Palmas, Tocantins, Brasil.

*Correspondência: Laboratório de Microbiologia Geral e Aplicada Universidade Federal do Tocantins - UFT, Av. NS 15, 109 Norte, Palmas, Tocantins, Brasil.CEP:77.010-090.e-mail julianaafmsilva@uft.edu.br

\section{Artigo recebido em 26/04/2017 aprovado em 31/08/2017 publicado em 03/10/2017.}

\section{RESUMO}

A intoxicação alimentar por estafilococos é uma das doenças transmitidas por alimentos (DTA) mais comuns e resulta da ingestão de enterotoxinas estafilocócicas (EE) pré-formadas em alimentos. Este trabalho teve como objetivo elaborar uma revisão sobre a ocorrência de Staphylococcus em alimentos, surtos de intoxicação estafilocócica, enterotoxinas comumente envolvidas em surtos e métodos de identificação de enterotoxinas estafilocócicas.No Brasil os dados do Sistema Nacional de Agravos e Notificações da Secretaria de Vigilância em Saúde SINANISVS, Ministério da Saúde, atribuem ao S. aureus a ocorrência de $7,7 \%$ dos surtos de origem alimentar no período compreendido entre 2000 a 2015. Para melhorar a caracterização de EE várias técnicas têm sido integradas na estratégia de diagnóstico, sendo os métodos mais utilizados para detectar as toxinas bacterianas nos alimentos: bioensaios, biologia molecular e imunológico. Os métodos convencionais de detecção de EE são de trabalho intensivo e incapaz de satisfazer as necessidades de detecção em tempo real. A biologia molecular baseada em PCR é um método viável, mais rápido e com resultados conclusivos. Os métodos cromatográficos são eficientes e sensíveis, porém, os requisitos da amostra, instrumentos caros e treinamento de pessoal limitam a sua aplicação.

Palavras-chave: Staphylococcus aureus. Intoxicação alimentar. Enterotoxinas estafilocócicas.

\section{ABSTRACT}

Staphylococcal food poisoning is one of the most common foodborne diseases (DTA) and results from ingestion of pre-formed staphylococcal enterotoxins (SE) in food. This work aimed to review the occurrence of Staphylococcus in food, outbreaks of staphylococcal intoxication, enterotoxins commonly involved in outbreaks and methods of identification of staphylococcal enterotoxins. In Brazil, data from the National Health and Aging System SINAN/ SVS, Ministry of Health, attribute to S. aureus the occurrence of $7.7 \%$ of food-borne outbreaks in the period from 2000 to 2015.In order to improve the characterization of EE, several techniques have been integrated into the diagnostic strategy, the most used methods being to detect bacterial toxins in food: bioassays, molecular biology and immunology. Conventional EE detection methods are labor-intensive and unable to meet real-time detection needs. PCR-based molecular biology is a viable, faster and conclusive method. Chromatographic methods are efficient and sensitive, however, sample requirements, expensive instruments and personnel training limit their application.

Keywords: Staphylococcus aureus. Food poisoning. Staphylococcal enterotoxins. 


\section{RESUMEN}

La intoxicación alimentaria estafilocócica es una de las enfermedades transmitidas por los alimentos (ETA) más común y resulta de la ingestión de la enterotoxina estafilocócica (EE) preformada en los alimentos. Este estudio tuvo como objetivo la revisión sobre la ocurrencia Staphylococcus en los alimentos, brotes de intoxicación alimentaria por estafilococos, enterotoxinas comúnmente involucradas en brotes y métodos de identificación de enterotoxinas estafilocócicas. La metodología empleada se basó en la investigación cualitativa y sistemas de información. En Brasil, los datos del Sistema Nacional de Agravos e Notificações da Secretaria de VigilânciaemSaúdeSINAMSVS, Ministerio de Salud, atribuyen al S. aureus la ocurrencia de un 7,7\% de los brotes de origen alimentario en el período de 2000 a 2015. Para mejorar la caracterización de EE, diversas técnicas se han integrado en la estrategia de diagnóstico y los métodos utilizados para detectar toxinas bacterianas en los alimentos: bioensayos, biología molecular e inmunológica. Los métodos convencionales de detección de EE son de trabajo intensivo e incapaz de satisfacer las necesidades de detección en tiempo real. La biología molecular basada en PCR es un método más rápido y con resultados concluyentes. Los métodos cromatográficos son eficientes y sensibles, sin embargo, los requisitos de la muestra, instrumentos caros y la capacitación del personal limitan su aplicación.

Descriptores: Staphylococcus aureus. Intoxicación alimentaria. Enterotoxina estafilocócica.

\section{INTRODUÇÃO}

A ocorrência de surtos de intoxicação alimentar é registrado em todo o mundo. No Brasil, são poucas as informações quanto às doenças transmitidas por alimentos. No entanto, as intoxicações estafilocócicas são muito comuns no país, sendo a maioria dos casos não investigada ou não notificada (PEREIRA et al., 1994). No período de 2000 a 2015, S. aureus foi diagnosticado como agente causal de 7,7\% dos surtos intoxicação alimentar ocorridos no Brasil (BRASIL, 2015).

A intoxicação alimentar por estafilococos é uma das doenças transmitidas por alimentos (DTA) mais comuns e resulta da ingestão de enterotoxinas estafilocócicas (EE) pré-formadas em alimentos (HENNEKINNE et al., 2012).

O diagnóstico de intoxicação alimentar por estafilococos de uma forma geral é confirmado pela identificação de contagens superior a $10^{5} \mathrm{UFC} \mathrm{g}^{-1}$ de $S$. aureus a partir de restos de alimentos ou pela detecção de EE (enterotoxinas estafilocócicas) remanescentes nos alimentos (SANTANA, 2006).
Para a detecção de $\mathrm{EE}$, vários métodos foram desenvolvidos como os biológicos,imunológicos e moleculares. O desenvolvimento das técnicas moleculares permitiu a utilização de ferramenta para detecção da sequência de nucleotídeos do gene responsável pela produção de enterotoxina pelos estafilococos (SANTANA et al., 2010).

Outros métodos para identificação e enumeração de enterotoxinas estafilocócicas em alimentos tem se destacado como promissores (WU et al., 2016).

Este trabalho teve como objetivo elaborar uma revisão sobre o Staphylococcus aureusem alimentos, surtos de intoxicaçãoestafilocócica, enterotoxinas comumente envolvidas em surtos e métodos de identificação de enterotoxinas estafilocócicas.

CARACTERIZAÇÃO DO STAPHYLOCOCCUS AUREUS 
Os estafilococos são bactérias Grampositivas, cujo diâmetro oscila entre 0.5 e 1.5 micras. Caracterizam-se porque dividem-se em grupos que assemelham com cachos de uva (HARRIS et al., 2002). Este grupo de bactérias são imóveis, não esporuladas e, geralmente, não capsulados, apresentando positividade para catalase (KONEMAN, 1997), com exceção das espécies $S$. saccharolyticuse, S. aureus subsp. anaerobius, que são catalase negativa (BERTRAND et al., 2002).

A superfície externa da maioria das cepas de S. aureus contém o fator de coagulação, coagulase ligada, que se liga ao fibrinogênio e o converte em fibrina insolúvel, sendo importante fator de virulência. A sua detecção é utilizada para identificação desta espécie (MURRAY, 2009).

Os estafilococos crescem em meios comuns, caldo ou ágar simples, $\mathrm{pH}=7$, à temperatura ótima de $37^{\circ}$ C. As colônias formadas em placa, após 18-24 horas de incubação, apresentam-se arredondadas, lisas e brilhantes. Outro meio importante para a identificação dos estafilococos é o ágar manitol-sal, seletivo para essa espécie, uma vez que o $S$. aureus consegue fermentar o manitol, produzindo ácido lático(SANTOS, 2007).

\section{CONDIÇÕES PARA CONTAMINAÇÃO, SOBREVIVÊNCIA E MULTIPLICAÇÃO EM ALIMENTOS}

\section{Fatores que Influenciam o Crescimento}

Os estafilococos são microrganismos mesófilos com temperatura de crescimento entre 7 e $47,8^{\circ} \mathrm{C}$ e podem produzir enterotoxinas termoresistentes a temperaturas entre 10 e $46^{\circ} \mathrm{C}$, com temperatura ótima entre 40 e $45^{\circ} \mathrm{C}$. $\mathrm{O}$ pH ideal para seu desenvolvimento varia entre 7 a 7,5, mas é possível a multiplicação em alimentos com $\mathrm{pH}$ variando entre 4,2 e 9,3(SANTANA et al., 2010).
Este grupo de microrganismos ainda tem a capacidade de sobreviver e se multiplicar em uma concentração de cloreto de sódio de até $15 \%$ e a produção de enterotoxina acontece em concentrações de sal de até $10 \%$, o que faz com que os alimentos curados também sejam veículos potenciais de intoxicação(SANTANA et al., 2010).

Quanto à atividade de água $\left(\mathrm{a}_{\mathrm{w}}\right)$ os estafilococos são únicos em sua capacidade de se multiplicarem em alimentos com valores de atividade de água inferiores ao normalmente considerados mínimos para outras bactérias halófilas. O valor mínimo de $\mathrm{a}_{\mathrm{w}}$ é 0,86 , apesar de já ter sido relatada a multiplicação desses micro-organismos em alimentos com $\mathrm{a}_{\mathrm{w}}$ de 0,83 (WONG et al., 2002; FRANCO et al., 2005). A presença de outros microrganismos também é um ponto importante, pois os estafilococos são considerados mal competidores (LOIR et al.,2003).

\section{Meios de Contaminação}

As infecções estafilocócicas podem ser causadas por bactérias do próprio indivíduo, de outros doentes ou de portadores sadios, como profissionais da saúde, iniciando após o contato com áreas traumatizadas da pele ou mucosas, permitindo ao microrganismo o acesso aos tecidos adjacentes ou à corrente sanguínea. No entanto, a infecção pode ficar localizada ou disseminar-se, o que depende da interação complexa entre os fatores de virulência do $S$. aureus e os mecanismos de defesa do hospedeiro. Nesse contexto, o $S$. aureus é a bactéria mais frequente na mucosa nasal (LOWY, 1998). Os portadores nasais podem, por meio das mãos, desempenhar papel importante na disseminação do microrganismo, principalmente por meio dos alimentos por eles manuseados (RADDI et al., 1998).

É a partir da cavidade nasal que o microrganismo atinge a epiderme, ar, água, solo, 
alimentos, ou qualquer outro objeto que entre em contato com o indivíduo. Os portadores nasais de $S$. aureus ao manipularem alimentos podem se tornar importantes fontes de contaminação para os alimentos (FRANCO, 2005; ASPERGER, 1994; LANCETTE et al.,1992).

\section{Reservatórios}

Os humanos são reservatórios naturais do $S$. aureus tendo sua pele e mucosas colonizadas por este microrganismo, o qual frequentemente integra-se a flora comensal do hospedeiro, caracterizando um estado de portador crônico. O indivíduo portador transmite o $S$. aureus por contato direto entre pessoas e as taxas de colonização na comunidade variam de $20 \%$ a $50 \%$, podendo aumentar entre pacientes e profissionais institucionalizados (CORDEIRO, 2011).

O estado de portador de $S$. aureus pode ser transitório ou permanente, estendendo-se por anos. Alguma condição que comprometa a integridade das defesas do hospedeiro, tais como trauma, procedimentos invasivos ou infecções viróticas, constituem oportunidades para a manifestação do potencial de virulência do $S$. aureus (FRANCO et $a l ., 2005)$.

É válido lembrar que, devido à sua capacidade de resistir à dessecação e ao frio, o $S$. aureus consegue permanecer viável por longos períodos em partículas de poeira, o que torna sua distribuição ainda mais ampla (CAVALCANTI et al., 2006).

\section{SURTOS DE INTOXICAÇÃO ALIMENTAR POR S. AUREUS}

A intoxicação alimentar por estafilococos é uma das doenças transmitidas por alimentos (DTA) mais comuns e resulta da ingestão de enterotoxinas estafilocócicas (EE) pré-formadas em alimentos por cepas enterotoxigênicas de $S$. Aureus (HENNEKINNE et al., 2012).

A ocorrência de surtos de intoxicação alimentar é registrada em todo mundo. Em 2008, 150 pessoas se reuniram para uma celebração de casamento em Baden-Wurttemberg, na Alemanha. Três horas depois da ingestão de uma variedade de alimentos, incluindo panquecas com recheio de frango picado, vários convidados apresentaram sintomas de gastroenterite aguda, como vômitos, diarréia, febre aguda. A investigação revelou que o possível agente causador do surto foi o $S$. aureus (JOHLER et al., 2013).

Em estudo recente investigou-se a epidemiologia molecular de $S$. aureus isolado de sete intoxicações por estafilococosentre 2006 e 2013 em Xi'an, noroeste da China. Um total de sete isolados de $S$. aureus associados a sete surtos por estafilococos foram obtidos e caracterizados naquela ocasião (LI GUANGHUI et al., 2014).

Mais de 100 indivíduos ficaram doentes depois de ingerirem uma variedade de sobremesas de uma padaria de Illinois. A equipe de investigação identificou desvios substanciais do atual Regulamento de Boas Práticas de Fabricação e apontou o S. aureus como possível agente etiológico (KIM et al., 2011).

Em estudo realizado com 203 cepas de $S$. aureus originadas de 83 surtos ocorridos em Tóquio, estas foram examinadas quanto ao seu tipo de coagulase e genótipo de EE ( HAIT et al., 2012).

No Brasil os dados do Sistema Nacional de Agravos e Notificações da Secretaria de Vigilância em Saúde SINANISVS, Ministério da Saúde, retratama ocorrência de surtos alimentares (fig.1) (BRASIL, 2015).

Figura 1. Notificações de surtos de origem alimentar. Brasil. 2000 a 2015. 


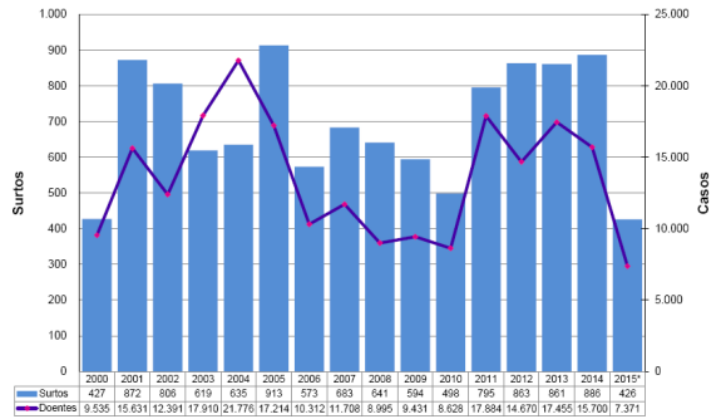

Quanto aos agentes etiológicos dos surtos

(fig 2), observa-se que o $S$. aureus foi associado a 7,7\% dos surtos no período analisado (BRASIL, 2015).

Figura 2: Agentes etiológicos responsáveis por surtos de DTA. Brasil. 2000 a 2015.
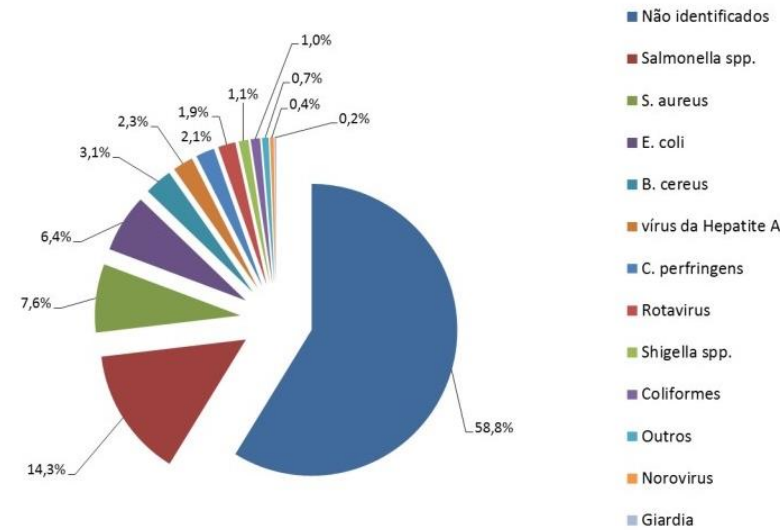

Ademais, a maioria dos surtos se deve ao manejo inadequado de alimentos na indústria ou em casa. Poucos surtos podem ser relacionados diretamente à contaminação durante o processamento de alimentos (WU et al., 2016).

Na região Sudeste do Brasil, doze pessoas foram acometidas de vômito e diarréia aproximadamente 4 horas após haverem ingerido bolo recheado, servido em uma festa de aniversário. No dia seguinte à festa $S$. aureus produtor de enterotoxina $\mathrm{A}$ foi isolado no bolo, fossa nasal, leito subungueal e, essencialmente, em uma ferida em fase de cicatrização, localizada na nuca da manipuladora, que dispunha de longa experiência na área de produção de alimentos (PEREIRA et al., 1994).

Ainda no Brasil, em 1998, em um surto de intoxicação alimentar, ocorrido com uma família que ingeriu queijo contaminado foi identificado um nível de contaminação para o S.aureus superior a $10^{6} \mathrm{UFCg}-$ ${ }^{1}$ (SABIONI et al., 1998).

Em outro surto de toxinfecção alimentar envolvendo 42 pessoas, ocorrido após a ingestão de uma refeição servida num restaurante do município de Passos, Minas Gerais, Brasil, foi relatado que trinta minutos após a ingestão dos alimentos, 31 pessoas adoeceram apresentando tontura, vômito, cólica e diarreia. Os alimentos suspeitos foram panqueca de frango, arroz, feijão, molho de tomate e pasta de grão de bico. Foram isolados na panqueca de frango contagens superiores a $2,0 \times 10^{8} \mathrm{UFC}$ de estafilococos produtores de enterotoxinas A, B e D por grama do alimento. Culturas isoladas a partir da região orofaríngea, sub-unguieal e mucosa nasal dos manipuladores de alimentos revelaram serem estes, portadores assintomáticos de cepas de $S$. aureus produtores de enterotoxinas A, B, C e D. Na mucosa nasal de um dos manipuladores foi isolada a cepa de $S$. aureus produtora de TSST-1. Os resultados obtidos indicaram os manipuladores como prováveis fontes de contaminação dos alimentos (CARMO et al., 2003).

\section{ENTEROTOXINAS E PATOGENICIDADE DO STAPHILOCOCCUS AUREUS}

Várias cepas S. aureus são produtoras enterotoxinas estafilocócicas (EE) em alimentos. Cinco EE clássicas (SEA, SEB, SEC, SED e SEE) são as causas mais comuns de DTA por $S$. aureus. Além disso, 16 novos tipos de EE ou superantígenos (SEG, SEH, SEI, SEJ, SEK, SEL, SEM, SEN, SEO, SEP, SEQ, SER, SES, SET, SEU e SEV) também foram descritas e avaliadas(KIM et al., 2011). 
Atualmente, 23 enterotoxinas foram identificadas como entidades sorológicas distintas, incluindo SEA, SEB, SEC, SED e SEE. Estas toxinas são proteínas básicas constituídas por 220-240 aminoácidos e têm pesos moleculares semelhantes de 25-30 kDa. As EE mais comuns são SEA e SEB. A SEA é mais freqüentemente envolvida na intoxicação alimentar causada pelo estafilococo. A SEB não está apenas envolvida na intoxicação alimentar, mas identificada como uma potencial arma biológica de guerra e terrorismo (WU et al., 2016).

Estudo realizado em cepas de $S$. aureus isoladas na mastite bovina mostraram que das 72 cepas de $S$. aureus estudadas, $66 \quad(91,7 \%)$ apresentaram produção de pelo menos um tipo de toxina, isoladamente ou em associação, evidenciando, portanto, elevado grau de toxigenicidade. Revelou, também, que $12(16,7 \%)$ produziram apenas um tipo de toxina, enquanto $10(13,9 \%)$ produziram, simultaneamente, até quatro EE, e que apenas seis $(8,3 \%)$ mostraram-se negativas na produção das toxinas SEA, SEB, SEC, SED e TSST-1(Toxina do choque tóxico) (FILHO et al., 2007).

As doenças provocadas pelo $S$. aureus podem ser decorrentes da invasão direta dos tecidos, ou exclusivamente, ser devidas às toxinas que ele produz. Dessa forma a análise do mecanismo de invasão do $S$. aureus revela que, no primeiro momento, essa bactéria adere à pele ou à mucosa para, em seguida, romper as barreiras do epitélio, comprometendo estruturas de ligações intercelulares, como desmossomos e junções de aderência. Após a invasão do epitélio, o $S$. aureus utiliza diversas estratégias para permitir a sua sobrevivência e proliferação no organismo hospedeiro (SANTOS, 2007).
Ainda, a capacidade de colonização e a patogenicidade do $S$. aureus são, portanto, uma consequência de seus fatores de virulência, os quais têm papel relevante na adesão celular, na captação de nutrientes e na sua evasão da resposta imunológica do hospedeiro. Assim o alto potencial infeccioso do $S$. aureus não está restrito apenas à sua facilidade de multiplicação e disseminação nos tecidos, mas também à produção de moléculas com grande poder patogênico, que incluem enzimas e toxinas (SANTOS, 2007).

As EE aumentam rapidamente a temperaturas adequadas $\left(20-37^{\circ} \mathrm{C}\right)$ e $\mathrm{pH}(4-7,4)$. O mecanismo de ação da intoxicação alimentar EE ainda não é totalmente compreendida. Alguns pesquisadores afirmam que a intoxicação resulta em uma resposta inflamatória em todo o trato gastrointestinal, caracterizada por danos no jejuno e 1́leo. Outros pesquisadores mostraram que as EE não atuam diretamente do trato gastrointestinal, mas indiretamente afeta a expressão de citocinas e metabólitos produzidos por células T, macrófagos, monócitos e mastocitos. As crianças podem adocecer por ingestão de $100 \mathrm{ng}$ de $\mathrm{EE}$, e as populações vulneráveis podem desenvolver intoxicação alimentar estafilocócica com alguns microgramas de toxina(WU et al., 2016).

\section{IDENTIFICAÇÃO E ENUMERAÇÃO DE $S$. AUREUS EM ALIMENTOS}

O diagnóstico de intoxicação alimentar por estafilococos de uma forma geral é confirmado pela identificação de pelo menos $10^{5} \mathrm{UFC} \mathrm{g}^{-1}$ de S. aureus a partir de restos de alimentos ou pela detecção de EE (enterotoxinas estafilocócicas) remanescentes nos alimentos. O S. aureus é sensível ao calor, podendo ser inativado durante o processamento de alimentos, no entanto suas enterotoxinas não o são. Dessa forma 
não é possível diagnosticar um surto de intoxicação alimentar enumerando o ECP (estafilococos coagulase-positva) em alimentos remanescentes ou detecção de genes em cepas isoladas (HENNEKINNE et al., 2012).

Os estafilococos coagulase positiva são estafilococos que produzem coagulase livre, enzima capaz de coagular plasma, e considerada como fator de virulência. O grupo ECP inclui S. aureus e outros estafilococos patogênicos enquanto que os ECN (estafilococos coagulase-negativa) são considerados não patogênicos (S. xylosus ou S. carnosus). Muitas técnicas confiáveis estão disponíveis e dependem de contagem direta em meios seletivos, métodos normalizados baseados em normas internacionais, ou em técnicas baseadas em DNA, reação em cadeia da polimerase (PCR) direcionada para genes específicos de $S$. aureus (CRETENET et al., 2011).

O S. aureus normalmente é enumerado usando técnicas microbiológicas com meios seletivos como Baird-Parker (BP) que pode ser complementado com fibrinogênio plasmático de coelho (BP-RPF). As normas internacionais atuais baseiam-se nestes dois meios BP e BP-RPF. Modificações destes meios foram descritos tais como complementação com outros compostos, sulfhamethazine, acriflavina ou polimixina e ainda ciclo-heximida (SMITH e BAIRDPARKER, 1964; DEVRIESE, 1981; BECKERS et al., 1984). Os meios cromogênicos revolucionaram os testes microbiológicos por garantir a identificação presuntiva do microrganismo de acordo com a coloração que este apresenta no meio semeado. As colônias são facilmente identificadas através da coloração diferenciada. Isso aumenta a eficiência dos testes e poupa tempo e custos comparados aos procedimentos tradicionais. Meios cromogênicos estão disponíveis comercialmente e oferecem detecção rápida, identificação e quantificação de $S$. aureus(CRETENET et al., 2011).

Além dos métodos normalizados, foram desenvolvidos métodos alternativos, também comercialmente disponíveis, alguns destes validados na França após estudos colaborativos e comparativos (Petrifilm ${ }^{\mathrm{TM}}$ staph Express, 3M e Rapidstaph Test, Biorad). Esses testes são baseados em meios seletivos que permitem a identificação presuntiva de $S$. aureus no prazo de 24 horas em vez das 48 horas dos métodos normalizados atuais (CRETENET et al., 2011).

Esforços têm sido dedicados ao desenvolvimento de técnicas que permitam a identificação e quantificação de cepas de $S$. aureus e ainda a virulência de genes associados com maior sensibilidade e rapidez do que os métodos atuais (STEPAN et al., 2004). Algumas técnicas de detecção baseadas em PCR têm sido aplicadas em alimentos, e orientado regiões específicos de $S$. aureus e alguns genes de enterotoxinas em ensaios de PCR simplex ou multiplex(CRETENET et al., 2011). A maioria dos genes EE é controlada pelo sistema agr. Os genes seb, sec e sed têm sido demonstrados como agr dependentes, enquanto os sea e sej independentes (LOIR et al., 2003). Os métodos moleculares baseados em DNA se mostram independentes de características específicas em condições artificiais (crescimento em meios laboratoriais), alcançando $100 \%$ de identificação, sendo essa uma vantagem em comparação com os métodos fenotípicos. No entanto, os métodos baseados em DNA podem levar à detecção de células mortas e resultar em contagens superestimadas de $S$. aureus nas amostras (CRETENET et al., 2011).

Enquanto $S$. aureus normalmente é enumerado usando técnicas microbiológicas com 
meios seletivos (BP e BP-RPF), três tipos de métodos, além dos métodos convencionais são utilizados para detectar toxinas bacterianas nos alimentos: bioensaios, biologia molecular e imunológico.

\section{IDENTIFICAÇÃO E ENUMERAÇÃO DE ENTEROTOXINAS EM ALIMENTOS}

As EEs são detectáveis nos alimentos a partir de contagens de população de células deS. aureusde $10^{6}$ ou mais por grama ou mililitro de alimento (SANTANA, 2006). Em pesquisas laboratoriais tem se observado que só é possível a detecção de enterotoxinas em contagens de $S$. aureus acima de $10^{6}$ UFC e na maioria dos alimentos associados às intoxicações, contagens de $10^{8}$ ou superiores raramente são relatadas (SANTANA et al., 2010).

\section{Métodos convencionais}

Os testes em animais estavam entre os primeiros métodos desenvolvidos para detectar EEs, e por apresentar baixa sensibilidade e especificidade, bem como uso limitado de testes em animais devido à origem e diferenças individuais, o método caiu em desuso (WU et al., 2016).A partir da identificação das proteínas enterotoxigênicas (BERGDOLL et al., 1959), as técnicas de detecção fundamentaram-se no uso de anticorpos preparados contra as enterotoxinas. Reações específicas de precipitação em agarose foram desenvolvidas, com destaque para o ensaio de imunodifusão em microlâminas, e OSP, Sensibilidade Ótima em Placa (PEREIRA et al., 2001).

Os testes sorológicos fazem parte dos métodos aplicados inicialmente para a detecção de EEs, incluindo o teste de difusão em gel e o teste de aglutinação (WU et al., 2016). O primeiro teste sorológico desenvolvido foi o método de imunodifusão baseado na reação em gel da enterotoxina com anticorpo específico, formando uma linha de precipitação (SU e WONG, 1997). O teste de aglutinação tem como base a aglutinação de células ou partículas revestidas com anticorpos. Em 1963 foi desenvolvido um teste de difusão para determinar SEB em cremes, frango, camarão e outros alimentos sólidos (HALL et al.,1963). Procedimentos de difusão de duplo gel foram relatados em ensaios com SEA e SEB em queijo, apresentando limites de detecção tão baixo como 0,02 e 0,05 $\mu \mathrm{g}$ por grama de queijo (READ et al., 1965). Em 1968 foi introduzido um teste de aglutinação de látex para a detecção de SEB, sendo utilizadas partículas de látex revestidas com anticorpos anti-SEB específicos como indicadores e o limite de detecção foi de $0,2 \mathrm{ng} / \mathrm{mL}$ (SALOMON e TEW, 1968). Kits de teste de aglutinação de látex passivo reverso (RPLA) foram desenvolvidos e aplicados para determinar EE em massas, carne, presunto, peru cozido e alguns produtos lácteos (PARK e SZABO,1986; ROSE et al., 1989). No entanto, os testes sorológicos são semi-quantitativos e carecem de especificidade e sensibilidade, dessa forma, alguns autores consideram que não foram desenvolvidos para a deteç̧ão de EE (WU et al., 2016).

\section{Identificação EE por métodos biomoleculares}

O desenvolvimento de técnicas moleculares viabilizou a aplicação de ferramenta para detecção da sequência de nucleotídeos do gene, responsável pela produção de enterotoxina pelos estafilococos (SANTANA et al., 2010). Os métodos biomoleculares incluem hibridação de ácidos nucléicos e Reação em Cadeia da Polimerase, PCR (WU et al., 2016). A PCR pode ser utilizada para detecção de diversos tipos de estafilococos enterotoxigênicos em culturas e alimentos. A detecção de EE por PCR foi relatada pela primeira vez por WILSON et al. (1991). Algumas variantes de PCR foram desenvolvidas para 
detectar EEs, tais como PCR multiplex, PCR em tempo real, PCR (RT-PCR), transcriptase inversa e amplificação isotérmica (SHYLAJA et al., 2010; RODRÍGUEZ et al., 2016; CHIANG et al., 2006; GOTO et al., 2007). Multiplex apresenta vantagem da detecção simultânea de várias EEs com diferentes iniciadores, em comparação com as outras técnicas. A PCR apresenta a vantagem de poder ser combinada com outras técnicas, como o número mais provável (NMP-PCR), e ensaio imunoenzimático ligado à enzima PCR (PCR-ELISA), que pode fornecer resultados sensíveis (MANTYNEN et al., 1997; GILLIGAN et al., 2000).

Entre as técnicas convencionais disponíveis, em comparação com testes em animais, a PCR é muito mais rápida e pode ser aplicada para detectar EEs na maioria dos alimentos (WU et al., 2016). No entanto, estes métodos apresentam duas limitações principais: primeiro, as cepas estafilocócicas são isoladas dos alimentos e, em segundo lugar, os resultados indicam a presença ou ausência de genes codificando EEs, mas não fornecem informação sobre a expressão destes genes em alimentos (HENNEKINNE et al., 2012). Dessa forma, esse método não pode ser utilizado para confirmação de $S$. aureus como agente causal de surto. Além disso, a detecção de rotina de microrganismos usando PCR pode ser dispendiosa e complicada. Todavia, é um método de abordagem rápida e sensível que pode caracterizar as cepas de S. aureus envolvidas em surtos, proporcionando informações valiosas(WU et al., 2016).

\section{Identificação EE por métodos de cromatografia}

As EEs são proteínas básicas que podem ser degradadas enzimaticamente em peptídeos, que podem ser subsequentemente separados por cromatografia líquida (LC) e analisados por colisão induzida pela dissociação no modo tandem por espectrometria de massa (MS/MS), proporcionando informação relativa ao analito com base nos pesos moleculares ou sequências primárias de aminoácidos (WU et al., 2016). Estudo utilizando a cromatografia líquida acoplado a fonte de ionização por electropulverização com espectrometria de massa(LCESI-MS) foi aplicado para detectar SEB em concentrações tão baixas quanto $3 \mathrm{pmol} / \mathrm{mL}$ (KIENTZ et al., 1997). Desde então, relatos bem sucedidos sobre testes quantitativos de detecção de EEs em sucos, leites, feijão verde, carne de frango e camarão utilizando LC-MS/MS têm sido relatados (CALLAHAN, 2006).

A LC-ESI-MS apresenta vantagens sobre as técnicas tradicionais, tais como evitar medidas preliminares para isolar as toxinas dos alimentos, a possibilidade de quantificação e limites mais baixos de detecção(WU et al., 2016).

\section{Identificação EE por imunoensaios}

O imunoensaio é um método analítico que é amplamente aplicado em vários campos, incluindo a análise baseada no reconhecimento específico entre antígenos e anticorpos. Os imunoensaios são sensíveis e específicos, rápidos de operar e podem ser usados para detectar EEs em amostras complexas sem prétratamento longo. A combinação de anticorpos como componente de reconhecimento com transdutor formam biossensores chamados imunossensores. Estes sensores podem ser classificados em três tipos principais: detecção óptica, técnicas de detecção eletroquímica e técnicas de detecção de massa (WU et al., 2016).

\section{Imunoensaios ópticos}

Métodos de detecção baseados em ótica apresentam elevada sensibilidade, alta frequência e 
monitorização em tempo real que pode tornar a detecção de EEs menos demorada, menor concentração da amostra, e facilidade no prétratamento da amostra (WU et al., 2016).

A técnica de ELISA (EnzymeLinkedImmunosor-bentAssay), é o método imunológico atualmente mais empregado para detecção de enterotoxinaestafilocócica. É um método colorimétrico que apresenta vantagens, por ser fácil de usar, específico e aplicável para rastreio de alto rendimento. Várias técnicas de ELISA foram desenvolvidas para a detecção de EEs em sobrenadantes de culturas e em amostras de alimentos, sendo o ELISA sanduíche o método mais comum, podendo detectar menos de $1 \mathrm{ng}$ de EE por $\mathrm{mL}$ de sobrenadante (SANTANA et al., 2010). Esta técnica é considerada a mais adequada para detecção de enterotoxinas estafilocócicas em alimentos, por apresentar desenvolvimento de cor diretamente proporcional à quantidade de enterotoxina presente na amostra, além de não necessitar de enterotoxinas altamente purificadas para o preparo da curva padrão. No entanto, a técnica pode apresentar falsos positivos devido às reações inespecíficas, principalmente com a proteína A e também falsos negativos em alimentos que passaram por tratamentos térmicos (SANTANA, 2006).

Os imunoensaios fluorescentes são a abordagem mais popular para a detecção de EEs.Tem sido utilizada uma variedade de marcadores no desenvolvimento de imunoensaios $\mathrm{EE}$ incluindo corantes fluorescentes ou nanopartículas fluorescentes que produzem sinais ópticos que podem ser correlacionados com a concentração da substância a analisar. Quando comparado com imunoensaios mediados por enzimas, determinou-se que os imunoensaios baseados em fluorescência possuíam maior potencial para fornecer análise de alta sensibilidade aumentada(WU et al., 2016). O primeiro imunoensaio fluorescente foi relatado em sanduíche para detecção de SEB (TEMPELMAN et al., 1996). Embora o método tenha apresentado variantes com aprimoramento significativo, vantagens potenciais para a detecção simultânea de múltiplas EEs devido a multi-corantes e nanopartículas fluorescentes como etiquetas, existem poucos relatos de determinação simultânea de múltiplas EEs (WU et al., 2016).

A quimioluminescência (CL) é uma tecnologia promissora com alta sensibilidade, ampla faixa linear e instrumentação simples. Os imunoensaios baseados em CL têm sido amplamente utilizados para a determinação de EE em alimentos (LUO et al., 2006; YANG et al., 2008; YANG et al., 2010). Em comparação com fluorescência e espectrofotometria UV-visível, os imunoensaios baseados em CL têm as vantagens de instrumentação simples, baixo custo e fácil automação devido à falta de uma fonte de excitação e filtros ópticos (WU et al., 2016).

A eletroquimioluminescência (ECL) é um meio de converter energia eletroquímica em energia radiativa na superfície de um eletrodo através de um potencial aplicado. Os sinais de luminescência podem ser obtidos a partir do estado excitação de um luminóforo ECL gerado na superfície do eletrodo durante a reação eletroquímica. Embora os biossensores ECL apresentem vantagens de rapidez e alta sensibilidade, configuração simplificada, baixo sinal de fundo e facilidade da miniaturização e ter recebido atenção considerada por parte de muitos, existem poucos relatos de aplicação de ECL à detecção de EE (RICHTER, 2004; MIÃO, 2008; WU et al., 2016). No entanto, foi desenvolvido um sistema automatizado de imunodetecção de ponto de 
atendimento (POC) combinando o formato ELISALOC (ELISA-lab-on-a-chip) com detector sensível ECL para a determinação de SEB que simplifica o procedimento e reduz os custos de testes (YANG et al., 2011).

\section{A Ressonância plasmática de} superfície(SPR) é um dos métodos mais sensíveis para a detecção de EE. Apresenta resposta sensível à superfície, sem etiquetas de detecção e capacidade de medição em tempo real. Numerosos estudos aplicaram SPR para a detecção de EE em leite, hotdogs, cogumelos, salada de batata, carne, presunto, dentre outros (RASOOLY e RASOOLY, 1999; RASOOLY, 2001; MEDINA, 2003; MEDINA, 2006).

\section{Imunoensaios eletroquímicos}

Método possível para a quantificação das EEs baseado na mudança de um sinal elétrico. $\mathrm{O}$ sinal elétrico pode ser observado como uma corrente, potencial, impedância ou condutância, que podem ser classificados como amperométrica, potenciométrica, impedimétrico e sensores condutométricos. Os imunoensaios eletroquímicos são simples, sensível, portátil, barato e reprodutível, tendo excelente compatibilidade com a tecnologia mais recente. $\mathrm{O}$ método de detecção de EEs com base em eletroquímica tem sido relatado por diversos autores (DONG et al., 2001; CHATRATHI et al., 2007; TANG et al., 2010; WU et al., 2013).

\section{Imunoensaios baseados em massa}

Os imunoensaios à base de massa são métodos de detecção sensível, em que a transdução é baseada em pequenas mudanças na massa. $\mathrm{O}$ meio de base de análise de massa depende do uso de cristais piezoelétricos e fitas ou fios ferromagnéticos amorfos. HARTEVELD e colaboradores introduziram um imunossensor cristal piezoelétrico para detecção de SEB com base em um esquema de competição utilizando os anticorpos policloniais (antiSEB), e o limite de detecção de $0,1 \mu \mathrm{g} / \mathrm{mL}$ foi obtido (HARTEVELD et al., 1997). Outros estudos têm sido relatados por pesquisadores (LIU et al., 2014; MARALDO e MUTHARASAN, 2007; LIN e TSAI, 2003; KARASEVA e ERMOLAEVA, 2015; RUAN et al., 2004). Embora o imunoensaio seja uma tecnologia confiável para detecção de EE, que exibe alta sensibilidade, ampla faixa linear e de viabilidade, eles exigem anticorpos de alta qualidade. A preparação dos anticorpos por meio de experiências de imunização de animais é tediosa e consumidora de tempo, além do que os anticorpos obtidos podem ser instáveis e suscetíveis a problemas de modificação (WU et al., 2016).

\section{Bioensaios em desenvolvimento}

Bioensaios baseados em aptâmeros com elevada afinidade e seletividade estão começando a emergir. Aptâmeros são moléculas curtas de ssDNA ou RNA selecionadas por meio de seleção in vitro ou por Evolução Sistemática de Ligantes por Enriquecimento Exponencial (SELEX). Os aptâmeros apresentam baixo peso molecular e estabilidade superior que pode suportar repetitiva desnaturação e renaturação. Em geral essas características únicas fazem dos aptâmeros um elemento ideal no reconhecimento de biossensores. Recentemente, aptâmeros têm sido elementos de reconhecimento alternativo aplicado à detecção de EEs (WU et al., 2016).

\section{Polímeros com impressão molecular}

(MIPs) incorporam uma nova classe de materiais que possuem alta seletividade e afinidade para as moléculas alvo. Os MIPs apresentam propriedades de reconhecimento molecular devido a cavidades produzidas na matriz de polímero que são complementares em tamanho e forma a molécula alvo 
(PILETSKY et al., 2001). São considerados mais estáveis quando comparados com proteínas e ácidos nucléicos, e podem resistir a condições mais duras, tais como temperatura elevada, $\mathrm{pH}$ extremo, pressão e solventes orgânicos. Além disso, a preparação dos MIPs não exige animais, que são essenciais para a produção de anticorpos. MIPs são elementos sensores estáveis e econômicos e são adequados para a substituição de recursos naturais receptores e anticorpos em ensaios. Vários métodos têm sido desenvolvidos para a determinação de EE baseado em MIPs como moléculas de reconhecimento para EEs (GUPTA et al., 2010; LIU et al., 2012; LIU et al., 2014).

\section{CONSIDERAÇÕES FINAIS}

Os estafilococos são patógenos de importância em doenças transmitidas por alimentos, e apesar da riqueza de informações disponíveis sobre sua virulência e suas enterotoxinas, eles ainda representam um campo ativo de pesquisa, o que certamente irá proporcionar novas descobertas nos próximos anos.

Para melhorar a caracterização de EE várias técnicas têm sido integradas na estratégia de diagnóstico. As diversas técnicas e ferramentas descritas na literatura para a detecção das EE apresentam vantagens e desvantagens. Os métodos

Todos os autores declararam não haver qualquer potencial conflito de interesses referente a este artigo.

\section{REFERÊNCIAS BIBLIOGRÁFICAS}

ASPERGER, H. Staphylococcus aureus. Groupof Experts A10/11. The significance of pathogenic microorganisms in raw milk. International dairy federation.. v.9405, p. 24-42, 1994. convencionais de detecção de EE são de trabalho intensivo e incapaz de satisfazer as necessidades de deteç̧ão em tempo real. A biologia molecular baseada em PCR é um método confiável, mais rápido e com resultados conclusivos. No entanto, destinam-se apenas à análise de DNA e não são indicados para detecção direta de EEs. Os métodos cromatográficos são eficientes e sensíveis, porém, os requisitos da amostra, instrumentos caros e treinamento de pessoal limitam a sua aplicação. Novas tecnologias, imunossensores combinados com ópticas, elétricas e as técnicas de transdutor de massa, são opções confiáveis.

Os bioensaios em desenvolvimento baseados em novos elementos de reconhecimento, tais como aptâmeros, peptídeos e MIPs, para a detecção de EE têm demonstrado características superiores em termos de sensibilidade, seletividade, rapidez e confiabilidade.No entanto, relatos de algumas dificuldades na aplicação de biossensores baseados em aptâmeros para detecção de Staphylococcus aureustem sido observado, a exemplo, dependência da seletividade com as condições da amostra, interações não específicas com a matriz e interações entre nanopartículas com proteínas séricas.

BECKERS, H.J.; VANLEUSDEN, F.M.; BINDSCHEDLER, O.; GUERRAZ, D. Evaluation of a pour plate system with a rabbit plasma bovine fibrinogen agar for the enumeration of Staphylococcus aureus in food. Canadian Journal of Microbiology. v.30,p. 470-474, 1989.

BERGDOLL, M.S.; SURGALLA, M.J.; DACK, G.M. Staphylococcal enterotoxin: Identification of a specific precipitating antibody with 
enterotoxinneutralizing property. Journal of Immunology, v.83, p.334-338, 1959.

BERTRAND, X.; HUGUENIN, Y.; TALON, D. Firstreport of a catalase-negativemethicillinresistantStaphylococcusaureus.

Diagnostic

Microbiology and Infectious Diseases, v.43, p.245246, 2012.

BRASIL, Ministério da Saúde, Secretaria de Vigilância em Saúde. Doenças Trasmitidas por Alimentos. Disponível em http://u.saude.gov.br/images/pdf/2015/novembro/0 9/ApresentaodadosgeraisDTA2015.pdf. Acesso em 30 de outubro de 2016.

CALLAHAN, J.H.; SHEFCHECK, K.J.; WILLIAMS, T.L.; MUSSER, S.M. Detection, confirmation, and quantification of Staphylococcal enterotoxin $B$ in food matrixes using liquid chromatography-mass spectrometry. Analytical Chemistry.v.78, 1789-1800, 2006.

CARMO, L.S.;SOUZA， D.R.; LINARDI， R.; VALTER, S.;SENA, M.J.; SANTOS, D.A. An outbreak of staphylococcal food poisoning in the Municipality of Passos, MG, Brazil. Brazilian Archives of Biologyand Technology.v.46, n.4, p.581-586, 2003.

CAVALCANTI, S.M.M.;FRANCA,E.R.; VILELA, M.A.; MONTENEGRO, F.; CABRAL, C.; MEDEIROS A.C.R. Estudo comparativo da prevalência de Staphylococcus aureus importado para as unidades de terapia intensiva de hospital universitário, Pernambuco, Brasil. Revista brasileira de epidemiologia.v. 9, n. 4, p.436-446, 2006.

CHATRATHI, M.P.; WANG, J.; COLLINS, G.E. Sandwich electrochemical immunoassay for the detection of Staphylococcal enterotoxin B based on immobilized thiolated antibodies. Biosensors \& Bioelectronics.v.22, p.2932-2938, 2007.

CHIANG, Y.C.; CHANG, L.T.; LIN, C.W.; YANG, C.Y.; TSEN, H.Y. PCR primers for the detection of
Staphylococcal enterotoxins K, L, and M and survey of Staphylococcal enterotoxin types in Staphylococcus aureusisolates from food poisoning cases in Taiwan. Journal of Food Protection. v.69, p.1072-1079, 2006.

CORDEIRO, M.M. Caracterização molecular de cepas de Staphylococcus aureus isolados no Hospital Municipal de Ipatinga/MG. Dissertação (Mestrado). Universidade Federal de Ouro Preto, OuroPreto, 2011 .

CRETENET, M.; EVEN, S.; LE LOIR, Y. Unveiling Staphylococcus aureusenterotoxin production in dairy products: a review of recent advances to face new challenges. Dairy Science \& Technology. v.91, p.127-150, 2011.

DEVRIESE, LA. Baird-Parker medium supplemented with acriflavine, polymyxins and sulfonamide for the selective isolation of Staphylococcus aureus from heavily contaminated materials. Journal of applied bacteriology.v.50, p. 351-357, 1981.

DONG, S.Y.; LUO, G.A.; FENG, J.; LI, Q.W.; GAO, H. Immunoassay of Staphylococcal enterotoxin C1 by ftir spectroscopy and electrochemical gold electrode. Electroanalysis.v.13, p. 30-33, 2001.

FRANCO, B.D.G. de M.; LANDGRAF, M. Microbiologia dos alimentos. São Paulo: Editora Atheneu, 2005.

FILHO, A.N.; FERREIRA, L.M.; AMARAL, L.A.; ROSSI JUNIOR,O.D.; OLIVEIRAR.P.Produção de enterotoxinas e da toxina da síndrome do choque tóxico por cepas de Staphylococcus aureus isoladas na mastite. Faculdade de Ciências Agrárias e Veterinárias - UNESP. Arquivo Brasileiro de Medicina Veterinária e Zootecnia. v.59, n.5, p.1316-1318, 2007.

GILligAN， K.; SHIPLEY， M.; STILES， B.; HADFIELD, T.; IBRAHIM, M.S. Identification of Staphylococcus aureus enterotoxins A and B genes 
by PCR-ELISA. Molecular and Cellular

Probes.v.14, n.2, p.71-78, 2000.

GOTO, M.; HAYASHIDANI, H.; TAKATORI, K.; HARA-KUDO, Y. Rapid detection of enterotoxigenicStaphylococcus aureusharbouring genes for four classical enterotoxins, SEA, SEB, SEC and SED, by loop-mediated isothermal amplification assay. Letters in Applied Microbiology.v.45, n.1, p.100-107, 2007.

GUPTA, G.; SINGH, P.K.; BOOPATHI, M.; KAMBOJ, D.; SINGH, B.; VIJAYARAGHAVAN, R. Molecularly imprinted polymer for the recognition of biological warfare agent Staphylococcal enterotoxin B based on surface plasmon resonance. Thin Solid Films. v.519, n.3, p.1115-1121, 2010.

HAIT, J.; TALLENT, S.; MELKA, D.; KEYS, C.; BENNETT, R. Staphylococcus aureus Outbreak Investigation of an Illinois Bakery. Journal of Food Safety.v.32, p. 435-444, 2012.

HALL, H.E.; ANGELOTTI, R.; LEWIS, K.H. Quantitative detection of Staphylococcal enterotoxin $\mathrm{B}$ in food by gel-diffusion methods. Public Health Reports.v.78, n.12, p.1089-1098, 1963.

HARRIS, L.G; FOSTER, S.J.; RICHARDS, R.G. Anintroductionto Staphylococcus aureus, and techniques for identifyingand quantifying S.aureusadhesins in relations to adhesion to biomaterials: Review. European Cells and Materials. v.4, n.2, p.39-60, 2002.

HARTEVELD, J.L.N.; NIEUWENHUIZEN, M.S.; WILS, E.R.J. Detection of Staphylococcal Enterotoxin B employing a piezoelectric crystal immunosensor. Biosensors and Bioelectronics. v.12, n.7, p.661-667, 1997.

HENNEKINNE, J.-A.; BUYSER, M.-L.; DRAGACCI, S. Staphylococcus aureus and its food poisoning toxins: characterization and outbreak investigation. FEMS Microbiology Reviews. v.36, n.4, p.815-836, 2012.
JOHLER， S.; TICHACZEK-DISCHINGER, p.s.; JÖRG, R.; SIHTO, H-M.; LEHNER, A.; ADAM, M.; STEPHAN, R. Outbreak of Staphylococcal Food Poisoning Due to SEA-Producing Staphylococcus aureus. Foodborne pathogens and disease. v.10, n.9, p.777-781, 2013.

KARASEVA, N.; ERMOLAEVA, T.A regenerable piezoelectric immunosensoron the basis ofelectropolymerizedpolypyrrole for highly selective detection of Staphylococcal enterotoxin A in foodstuffs. Microchimica Acta.v.182, p.1329-1335, 2015 .

KIENTZ, C.E.; HULST, A.G.; WILS, E.R. Determination of Staphylococcal enterotoxin B by on-line (micro) liquid chromatography-electrospray mass spectrometry. Journal of Chromatography A. v.757, n.1-2, p.51-64, 1997.

KIM, N.H.;YUN, A.-R.; RHEE, M.S. Prevalence and classification of toxigenic Staphylococcus aureus isolated from refrigerated ready-to-eat foods (sushi, kimbab and California rolls) in Korea. Journal of Applied Microbiology. v.111, n.6, p.1456-1464, 2011.

Koneman E.W.; Allen, S.D.; Janda, W.M.; Schereckenberger, P.C.; Winn, W.C.J. The grampositive cocci: Staphylococci and related organisms. Atlas and Text book of Diagnostic Microbiology. p.539-576, 1997.

LANCETTE, G.A.; TATINI, S.R.Staphylococcus aureusIn:VANDRZANT, C. (Ed.). Compendium of methods for the microbiological examination of foods. Washington, American Public Health Association; 1992.

LIN, H.C.; TSAI, W.C. Piezoelectric crystal immunosensor for the detection of Staphylococcal enterotoxin B. Biosensors and Bioelectronics.v.18, n.12, p.1479-1483, 2003.

LIU, N.; LI, X.L.; MA, X.H.; OU, G.R.; GAO, Z.X. Rapid and multiple detections of Staphylococcal

Revista Desafios - v. 04, n. 04, 2017 
enterotoxins by two-dimensional molecularly imprinted film-coated QCM sensor. Sensors and Actuators B: Chemical.v.191, p.326-331, 2014. LIU, N.; ZHAO, Z.; CHEN, Y.; GAO, Z. Rapid detection of Staphylococcal enterotoxin B by twodimensional molecularly imprinted film-coated quartz crystal microbalance. Journal Analytical Letters. v.45, n.2-3, p.283-295, 2012.

LOIR, Y.LE; BARON, F.; GAUTIER, M. Staphylococcusaureus and food poisoning. Genetic and Molecular Research.v.2, n.1, p.63-76, 2003.

LOWY, F.D. Staphylococcus aureus infections. The

New England Journal of Medicine.v.339, n.8, p.520-532, 1998.

LUO, L.R.; ZHANG, Z.J.; CHEN, L.J.; MA, L.F. Chemiluminescent imaging detection of Staphylococcal enterotoxin $\mathrm{C} 1$ in milk and water samples. Food Chemistry.v.97, n.2, p.355-360, 2006.

MÄNTYNEN, V.; NIEMELÄ, S.; KAIJALAINEN, S.; PIRHONEN, T.;LINDSTRÖM, K. MPN-PCRQuantification method for Staphylococcal enterotoxin $\mathrm{C} 1$ gene from fresh cheese. International Journal of Food Microbiology.v.36, n.2-3, p.135-143, 1997. MARALDO, D.; MUTHARASAN, R. Detection and confirmation of Staphylococcal enterotoxin B in apple juice and milk using piezoelectric-excited millimeter-sized cantilever sensors at 2.5 fg/mL.Analytical Chemistry.v.79, n.20, p.76367643, 2007.

MEDINA, M.B. A biosensor method for detection of Staphylococcal enterotoxin A in raw whole egg. Journalof Rapid Methods and Automation Microbiology. v.14, n.2, p.119-132, 2006.

MEDINA, M.B. Detection of Staphylococcal enterotoxin B (SEB) with surface plasmon resonance biosensor. Journalof Rapid Methods and Automation Microbiology.v.11, n.3, p.225-243, 2003.
PARK, C.E.; SZABO, R. Evaluation of the reversed passive latex agglutination (RPLA) test kits for detection of Staphylococcal enterotoxins A, B, C, and $\mathrm{D}$ in foods. Canadian Journal of Microbiology.v.32, n.9, p.723-727, 1986.

PEREIRA, M.L.; CARMO, L.S.; PEREIRA, J.L. Comportamento de estafilococos coagulase negativos pauciprodutores de enterotoxinas em alimentos experimentalmente inoculados. Ciência e Tecnologia de Alimentos, v.21, n.2, p.171-175, 2001.

PEREIRA, M.L.; CARMO, L.S.; SANTOS, E.J.; BERGDOLL,M.S.Staphylococcal food poisoning from cream filled cake in a metropolitanarea of South-EasternBrazil. Revista de Saúde Pública. v.28, n.6, p.406-409, 1994.

PILETSKY, S.A.; PILETSKA, E.V.; BOSSI, A.; KARIM, K.; LOWE, P.; TURNER, A.P. Substitution of antibodies and receptors with molecularly imprinted polymers in enzyme-linked and fluorescent assays. Biosensors and Bioelectronics.v.16, p.701707, 2001.

RADDI, M.S.G.; LEITE, C.Q.F.; MENDONÇA, C.P. Staphylococcus aureus: portadores entre manipuladores de alimentos. Revista de Saúde Pública.v.22, n.1, p.36-40, 1988.

RASOOLY, A. Surface plasmon resonance analysis of Staphylococcal enterotoxin B in food. Journal of Food Protection. v.64, n.1, p.37-43, 2001.

RASOOLY, L.; RASOOLY, A. Real time biosensor analysis of Staphylococcal enterotoxin A in food.

International JournalFood Microbiology.v.49, n.3, p.119-127, 1999.

READ, R.B.; BRADSHAW, J.R.; PRITCHARD, W.L.; BLACK, L. Assay of Staphylococcal enterotoxin from cheese. Journal Dairy of Science.v.48, n.4, p.420-424, 1965.

RICHTER, M.M. Electrochemiluminescence (ECL). Chemical Reviews.v.104, n.6, p.3003-3036, 2004. 
RODRÍGUEZ,A.; GORDILLO, R.; ANDRADE, M.; CÓRDOBA, J.; RODRÍGUEZ, M. Development of an efficient real-time PCR assay to quantify enterotoxin-producing Staphylococci in meat products. Food Control. v.60, p.302-308, 2016.

ROSE, S.A.; BANKES, P.; STRINGER, M. Detection of Staphylococcal enterotoxins in dairy products by the reversed passive latex agglutination (SET-RPLA) kit. International Journal of Food Microbiology. v.8, p.65-72, 1989.

RUAN， C.; ZENG， K.F.; VARGHESE， O.K.; GRIMES, C.A. A Staphylococcalenterotoxin B magnetoelasticimmunosensor. Biosensors and Bioelectronics.v.20, n.3, p.585-591, 2004.

SABIONI, J.G.; HIROOKA, E.Y.; SOUZA, M. de L.R. de. Intoxicação alimentar por queijo Minas contaminado com Staphylococcus aureus. Revista de Saúde Pública.v. 22, n.5, p. 458-461, 1988.

SALOMON, L.L.; TEW, R.W. Assay of Staphylococcal enterotoxin B by latex agglutination. Experimental Biology and Medicine.v.129, p.539$542,1968$.

SANTANA, E.H.W. Determinação do perigo de consumo do leite cru relacionado a intoxicação estafilocócica. Londrina, PR. Tese de Doutorado. Universidade Estadual de Londrina - UEL; 2006. SANTANA, E.H.W.; BELOTI, V.; ARAGONALEGRO, L.C.; MENDONÇA, M.B.O.C. Estafilococos em alimentos. Arquivos do Instituto Biológico.v. 77, n.3, p.545-554, 2010.

SANTOS, A.L.; SANTOS, D.O.; FREITAS, C.C.; FERREIRA, B.L.A.; AFONSO, I.F.; RODRIGUES, C.R.; CASTRO, H.C. Staphylococcus aureus: visitando uma cepa de importância hospitalar.Jornal Brasileiro de Patologia e Medicina Laboratorial. vol.43, n.6, p.413-423, 2007.

SHYLAJA, R.; MURALI, H.; BATRA, H.; BAWA, A. A novel multiplex PCR system for the detection of Staphylococcal enterotoxin B, TSST, Nuc and Fem genes of Staphylococcus aureus in food system. Journal Food Safety. v.30, n.2, p.443-454, 2010. SMITH, B.A.; BAIRD-PARKER, A.C. The use of sulphamezathine for inhibiting Proteus spp. on BairdParker's isolation medium for Staphylococcus aureus. Journal of Applied Microbiology. v.27, n.1, p.78-82, 1964.

STEPAN, J.; PANTUCEK, R.; DOSKAR, J. Molecular diagnostics of clinically important staphylococci. Folia Microbiologica. v.49, n.4, p.353-386, 2004.

SU, Y-C.; WONG, A.C.L. Current perspectives on detection of staphylococcal enterotoxins. Journal of Food Protection, v.60, n.2, p.195-202, 1997.

TANG, D.P.; TANG, J.; SU, B.L.; CHEN, G.N. Ultrasensitive electrochemical immunoassay of Staphylococcal enterotoxin B in food using enzymenanosilica-doped carbon nanotubes for signal amplification. Journal of Agricultural andFood Chemistry.v.58, p.10824-10830, 2010.

TEMPELMAN, L.A.; KING, K.D.; ANDERSON, G.P.; LIGLER, F.S. Quantitating Staphylococcal enterotoxin B in diverse media using a portable fiberoptic biosensor. Analytical Biochemistry.v.233, p.50-57, 1996.

WILSON, I.G.; COOPER, J.E.; GILMOUR, A. Detection of enterotoxigenicStaphylococcus aureus in dried skimmed milk: Use of the polymerase chain reaction for amplification and detection of Staphylococcal enterotoxin genes entband entcl and the thermonuclease gene nuc. Applied and Environmental Microbiology. v.57, n.6, p.17931798, 1991.

WONG, A.C.L.; BERGDOLL, M.S. Staphylococcal food poisoning. In: CLIVER, D.O; RIEMANN, H.P. Foodborne Diseases . Amsterdam: Academic Press, p.231-248; 2002.

WU, L.Y.; GAO, B.; ZHANG, F.; SUN, X.L.; ZHANG, Y.Z.; LI, Z.J. A novel electrochemical 
immunosensor based on magnetosomes for detection of staphylococcal enterotoxin B in milk. Talanta. v.106, p.360-366, 2013.

WU, S.; DUAN, N.; GU, H.; HAO, L.; Y.E, H.; GONG, W.; WANG, Z. A Review of the Methods for Detection of Staphylococcus aureus Enterotoxins. Toxins.v.8(7),2016.doi:10.3390/toxins8070176.

YANG, M.H.; KOSTOV, Y.; BRUCK, H.A.; RASOOLY, A. Carbon nanotubes with enhanced chemiluminescence immunoassay for CCD-based detection of Staphylococcal enterotoxin B in food. Analytical Biochemistry.v.80, p.8532-8537, 2008. YANG, M.H.; SUN, S.; KOSTOV, Y.; RASOOLY, A. An automated point-of-care system for immunodetection of Staphylococcal enterotoxin B. Analytical Biochemistry.v.416, p.74-81, 2011. YANG, M.H.; SUN, S.; KOSTOV, Y.; RASOOLY, A. Lab-on-a-chip for carbon nanotubes based immunoassay detection of Staphylococcal enterotoxin B (SEB). Lab Chip. n. 10, p.1011-1017, 2010. 